\section{Case Report}

Korean J Transplant 2020;34:293-301

https://doi.org/10.4285/kjt.20.0027
Received July 1, 2020

Revised July 19, 2020

Accepted July 20, 2020

Corresponding author: Shin Hwang Department of Surgery, Asan Medical Center, University of Ulsan College of Medicine, 88 Olympic-ro 43-gil, Songpa-gu, Seoul 05505, Korea Tel: +82-2-3010-3930

Fax: +82-2-3010-6701

E-mail: shwang@amc.seoul.kr

(C) The Korean Society for Transplantation This is an Open Access article distributed under the terms of the Creative Commons Attribution Non-Commercial License (http://creativecommons.org/licenses/ by-nc/4.0/) which permits unrestricted non-commercial use, distribution, and reproduction in any medium, provided the original work is properly cited.

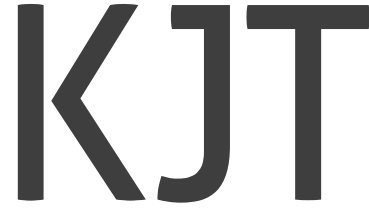

pISSN 2671-8790

elSSN 2671-8804

\title{
Unification venoplasty of the outflow hepatic vein for laparoscopically harvested left liver grafts in pediatric living donor liver transplantation
}

\author{
Jung-Man Namgoong', Shin Hwang ${ }^{1}$, Ki-Hun Kim', Gil-Chun Park', Kyung Mo Kim², \\ Seak Hee $\mathrm{Oh}^{2}$, Hwui-Dong Cho', Hyunhee Kwon', Yong Jae Kwon ${ }^{1}$ \\ 1Department of Surgery, Asan Medical Center, University of Ulsan College of Medicine, Seoul, Korea \\ ${ }^{2}$ Department of Pediatrics, Asan Medical Center, University of Ulsan College of Medicine, Seoul, Korea
}

Laparoscopically harvested left liver (LL) grafts have drawbacks with respect to the size and shape of graft hepatic vein orifices. We present two cases of pediatric living donor liver transplantation (LDLT) using laparoscopically harvested LL grafts and describe refined surgical techniques for graft hepatic vein venoplasty. The first case was a boy aged 4 years and 5 months, with hepatoblastoma. The donor was his 35 -year-old mother, and $\mathrm{LL}$ graft weighed $315 \mathrm{~g}$. Two separate openings of the graft at the left hepatic vein (LHV) and middle hepatic vein (MHV) were unified through septotomy and septoplasty, and cryopreserved vein homograft patch was attached. Standard procedures of LDLT were performed. This patient recovered uneventfully and has been doing well for 4 years without tumor recurrence. The second case was a 6-year-old girl with ornithine transcarbamylase deficiency. The donor was her 35 -year-old mother, and the LL graft weighed $310 \mathrm{~g}$. Two separate openings of graft MHV, with segment III and segment II veins, were unified through septoplasty, and vein patch was attached. Standard procedures of LDLT were performed. This patient has been doing well for 4 years. In conclusion, separate graft hepatic vein openings are a drawback of laparoscopically harvested LL grafts, which thus require unification venoplasty of customized design individually tailored for LL graft and pediatric recipient.

Keywords: Left hepatic vein; Venoplasty; Vein patch; Stenosis; Pediatric transplantation

\section{INTRODUCTION}

Living donor hepatectomy performed using total laparoscopy has definite merit for the cosmetic aspect of the donor's abdominal wound [1-6]. However, there are drawbacks of the liver grafts, in which the graft hepatic vein stump is very short because it is transected by an endoscopic vascular stapler, and the stapled stump of the graft side should be excised. Therefore, such condition often makes the graft hepatic vein orifice unsuitable for direct anastomosis.

A left liver (LL) graft used for living donor liver transplantation (LDLT) has two outflow veins, the left hepatic vein (LHV) and middle hepatic vein (MHV). In the LL grafts harvested through open surgery, the shapes of the graft outflow vein orifices appear to be a single orifice or 


\section{HIGHLIGHTS}

- Laparoscopically harvested left liver grafts has drawback of separate graft hepatic vein openings.

- It requires unification venoplasty of customized design individually tailored for the left liver graft and pediatric recipient.

similar to a figure of 8; thus, they require only a simple venoplasty. In contrast, in the LL grafts harvested through laparoscopic surgery, the stumps of the LHV and MHV are usually completely separate [5]; therefore, complex unification venoplasty is recommended and necessary to achieve best results. The surgical technique of unification venoplasty for laparoscopically harvested LL grafts is different from that for laparoscopically harvested left lateral section grafts. We herein present two cases of pediatric LDLT using a laparoscopically harvested LL graft and describe the refined surgical techniques for unification of LHV and MHV orifices.

\section{CASE REPORT}

This study, a retrospective review, was approved by the Institutional Review Board of Asan Medical Center (IRB No. 2020-0836). Owing to the retrospective design, the requirement for informed consent was waived.

\section{Case 1}

The patient was a boy aged 4 years and 5 months with previously diagnosed hepatoblastoma. The tumor was shown to be a hepatoblastoma of the epithelial type as seen on a percutaneous liver biopsy (Fig. 1A) and classified as a pretreatment extent of disease (PRETEXT) stage IV tumor. After five cycles of systemic chemotherapy, the hepatic tumor was markedly reduced in size and number (Fig. 1B), and there was no evidence of distant metastasis on fluorodeoxyglucose-positron emission tomography (Fig. 1C). Thus, LDLT was planned to treat the residual tumors. At LDLT operation, the patient's height was $105 \mathrm{~cm}$ and weight was $17 \mathrm{~kg}$.

The donor in this case was the patient's 35-year-old mother. Computed tomography (CT) volumetry showed that the estimated volume of the left hemiliver was $340 \mathrm{~mL}$ (Fig. 2). The LL graft was harvested using a totally laparo-
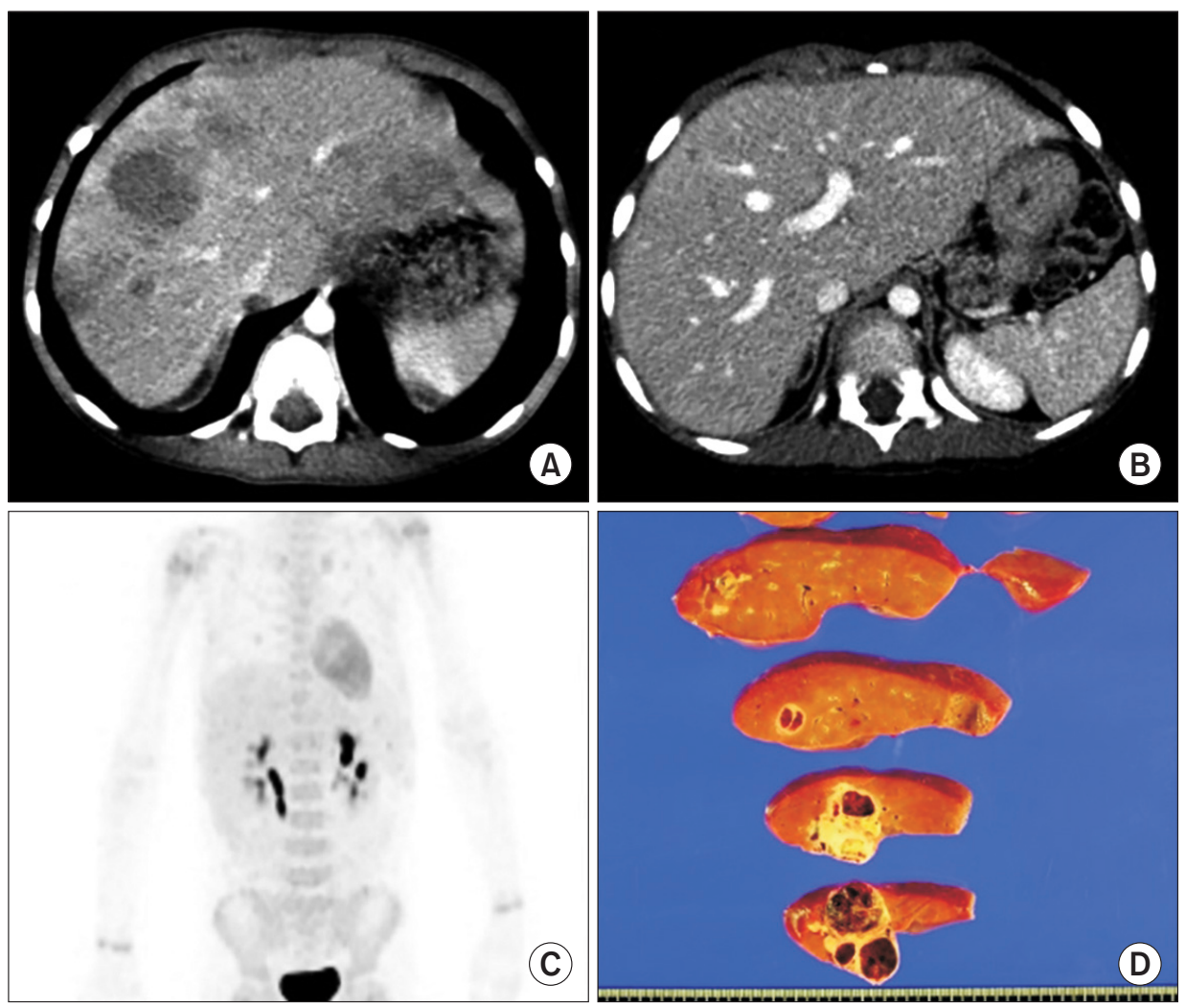

Fig. 1. Pretransplant findings of case No. 1. Computed tomography scans obtained 6 months (A) and 1 month (B) before transplantation show definite reduction in the size and number of hepatoblastoma. (C) Fluorodeoxyglucose-positron emission tomography shows no evidence of distant metastasis. (D)The explant liver shows multiple residual hepatoblastomas. 

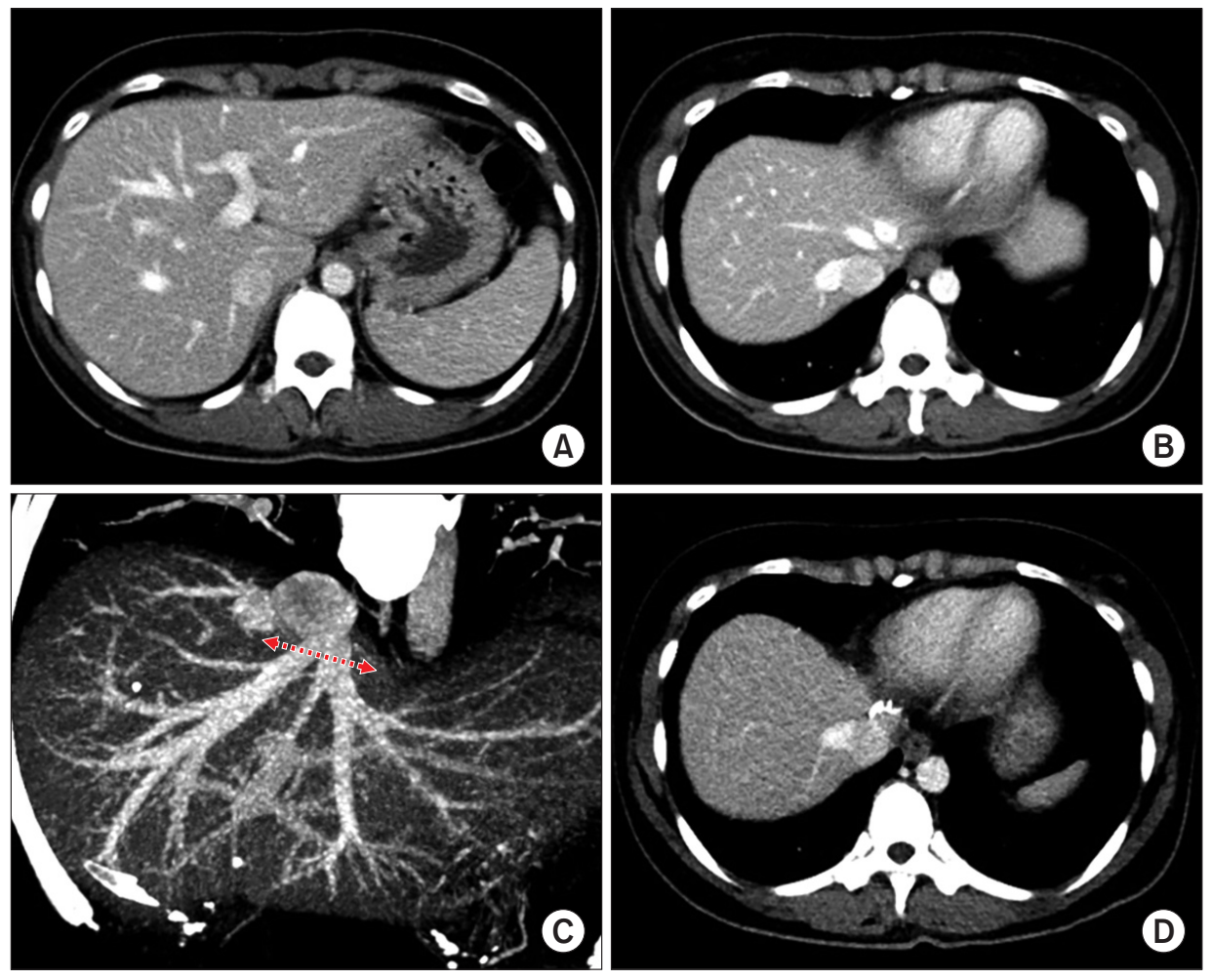

Fig. 2. Preoperative imaging studies of the living donor of case No. 1. Computed tomography scans show the shape of the left liver $(A)$ and the anatomy of the left and middle hepatic veins $(B, C)$. The arrow indicates the line of hepatic vein transection. (D) Computed tomography performed 1 week after the operation shows the location of hepatic vein transection by an endovascular stapler. scopic approach and delivered through a suprapubic incision. The detailed procedures of the totally laparoscopic LL graft harvest have been presented in a previous report [5]. The LL graft weighed $315 \mathrm{~g}$, with a graft-recipient weight ratio (GRWR) of $2.6 \%$. There were two separate openings (LHV and MHV) in the graft (Fig. $3 \mathrm{~A}$ and $\mathrm{B}$ ). The intervening hepatic parenchyma between these openings was excised through a septotomy (Fig. $3 \mathrm{C}$ and D), and then a unification septoplasty was performed (Fig. 3E). Next, a small superficial branch of the LHV was opened, and unification suture was performed to widen the orifice further. Then, an incision was made at the medial wall of the MHV trunk, and a patch of cryopreserved external iliac vein homograft was attached (Fig. 3F and G), which made the graft outflow vein orifice $4 \mathrm{~cm}$ in transverse diameter (Fig. $3 \mathrm{H}$ ).

Recipient hepatectomy was performed according to standard procedures. After total clamping of the inferior vena cava (IVC), the hepatic parenchyma was incised using a surgical knife, leaving the bulk of the hepatic parenchyma around the hepatic vein trunks. After the native liver was taken out, the attached hepatic parenchyma was forcefully pulled out to detach it from the hepatic vein stumps, which made the hepatic vein stump walls long and thick. The IVC wall septa between the right hepatic vein and MHV and the MHV and LHV were consecutively transected to form a single large hepatic vein orifice. The transverse diameter of this unified hepatic vein orifice was approximately $4 \mathrm{~cm}$. At the initiation of the graft implantation, we tagged the right and left corners of the graft and the recipient's hepatic vein orifices with 5-0 polydioxanone (PDS) to match their sizes. Then, we performed continuous sutures of the posterior wall continued first from the left corner in the 6 o'clock direction, and then the suturing continued toward the right corner after meticulous size matching. Continuous running suturing continued to the anastomosis of the anterior wall. After injecting heparinized saline into the IVC lumen, we completed the graft hepatic vein reconstruction. Thereafter, the branch patch of the recipient's portal vein was stretched toward the graft portal vein, and continuous suturing with a $6-0$ PDS was performed for portal vein reconstruction. The graft left hepatic artery was anastomosed with the recipient's left hepatic artery branch under surgical microscopy. Hepaticojejunostomy using a Roux-en-Y jejunal limb was performed for biliary reconstruction.

The pathology report revealed that the multiple residual hepatoblastomas were epithelial type with fetal subtypes with sizes up to $4.5 \mathrm{~cm}$. Tumor necrosis of $70 \%$ 

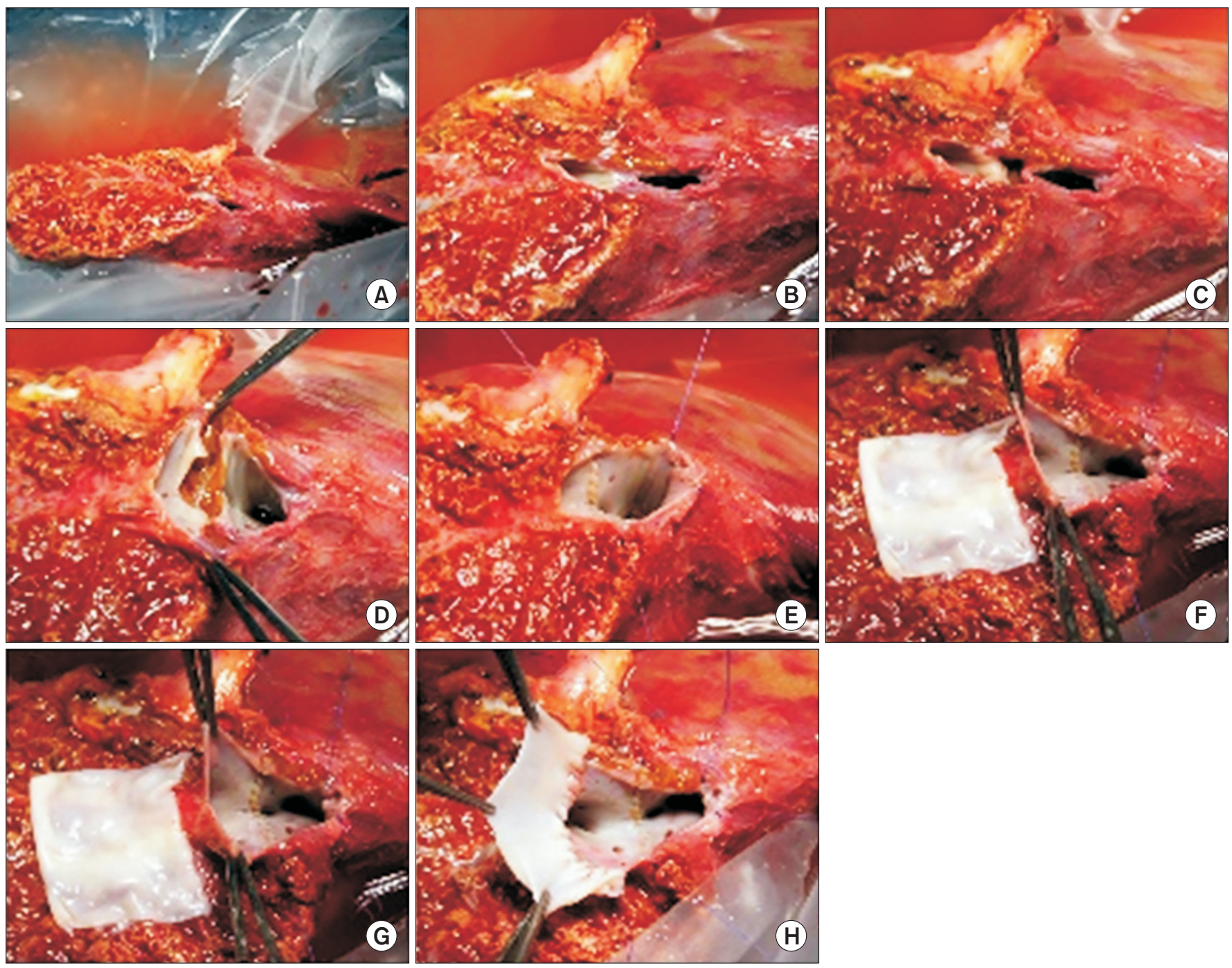

Fig. 3. Intraoperative photographs of the graft hepatic vein venoplasty on the back table in case No. 1. There were two separate openings, of the left hepatic vein (LHV) and middle hepatic vein (MHV) (A, B). The intervening hepatic parenchyma between these openings was excised through a septotomy (C, $D)$, and then a unification septoplasty was performed (E). A small superficial branch of the LHV was opened and a unification suture was performed. An incision was made at the medial wall of the MHV trunk, and a cryopreserved vein homograft patch was attached $(F, G)$, which made the graft outflow vein orifice $4 \mathrm{~cm}$ in transverse diameter $(\mathrm{H})$.

without microvascular invasion and lymph node metastasis was detected (Fig. 1D). This patient recovered uneventfully without any surgical complication (Fig. 4AC). He has been doing well for 4 years to date without any sign of tumor recurrence (Fig. 4D).

\section{Case 2}

The patient was a 6-year-old girl who suffered from ornithine transcarbamylase (OTC) deficiency (Fig. 5A). This disorder was diagnosed using OTC gene sequencing, in which the nucleotide mutation included c. $-441 \mathrm{~A}>\mathrm{G}$ and c. $-359 \mathrm{G}>\mathrm{A}$. The patient was frequently in a lethargic state and vomiting, with a noted elevation in blood ammonia levels. She also had been diagnosed with Duchenne muscular dystrophy. Thus, we planned to perform LDLT. At the LDLT operation, the patient's height and weight were 109 $\mathrm{cm}$ and $17 \mathrm{~kg}$, respectively. One day before the LDLT operation, continuous renal replacement therapy was initiated to control the symptoms of OTC deficiency.

The donor was the patient's 35-year-old mother. CT 

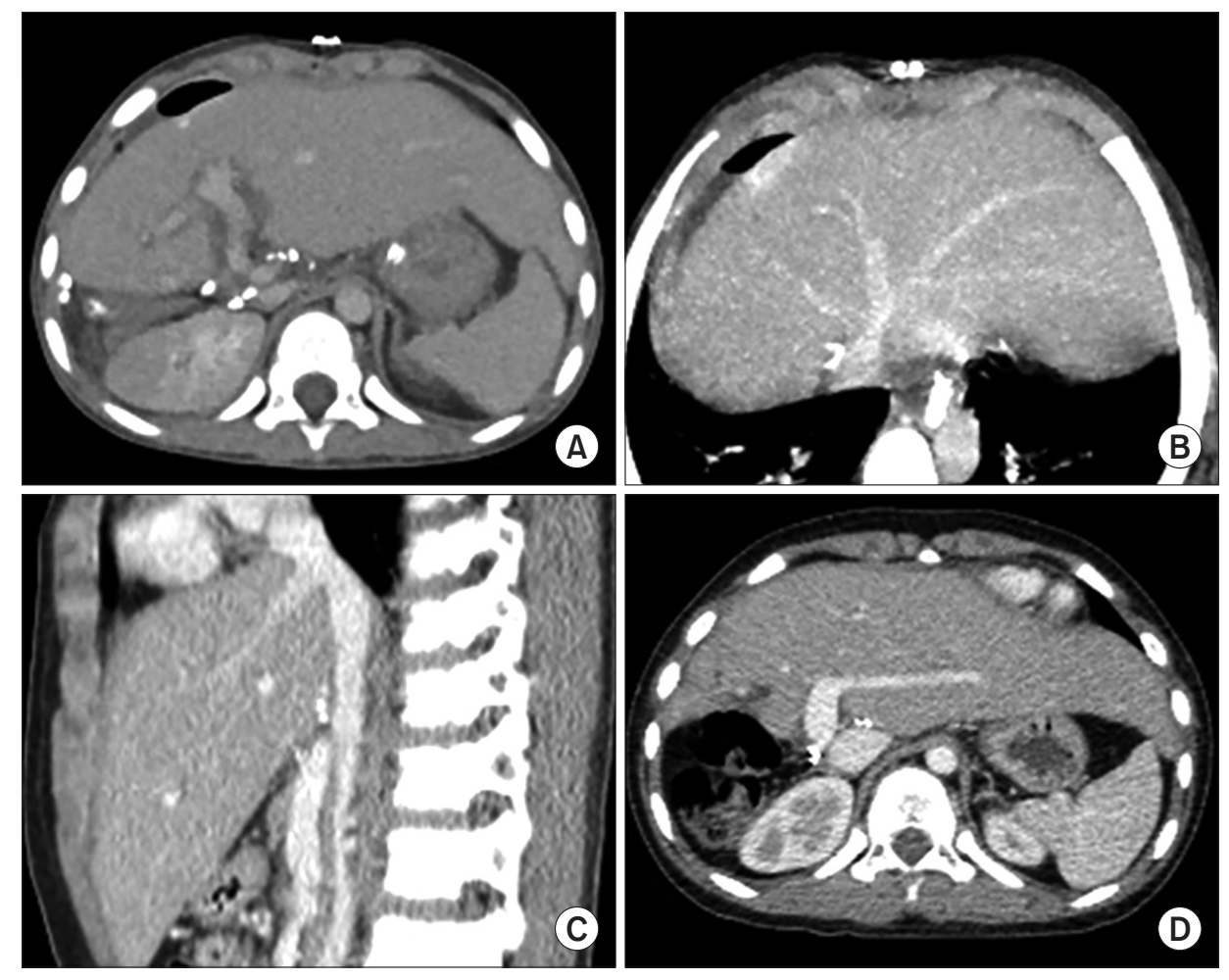

Fig. 4. Posttransplant computed tomography (CT) follow-up of case No. 1. (A) CT scan obtained 4 days after transplantation shows uneventful graft implantation. (B, C) CT scans obtained 14 days after transplantation show an uneventful reconstruction of the graft hepatic vein. (D) CT scan obtained 4 years after transplantation shows no evidence of tumor recurrence.
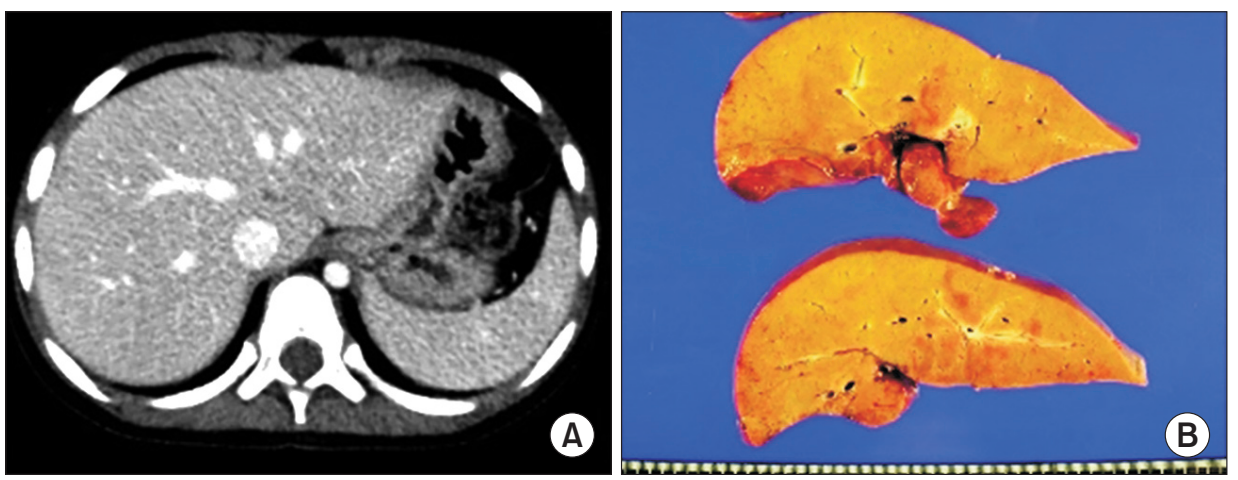

Fig. 5. Pretransplant findings of case No. 2. (A) Computed tomography scan obtained 1 month before transplantation shows no evidence of definite liver cirrhosis, compatible with metabolic disease. (B) The explant liver shows moderate fatty change and perivenular fibrosis. volumetry showed that the estimated volume of the left hemiliver was $330 \mathrm{~mL}$ (Fig. 6). The LL graft was harvested by a total laparoscopic approach and delivered through the suprapubic incision. The LL graft weighed $310 \mathrm{~g}$, with a GRWR of $1.8 \%$. There were two separate openings of the MHV, with segment III and segment II veins at the graft (Fig. $7 \mathrm{~A}$ and $\mathrm{B}$ ). A unification septoplasty was performed (Fig. $7 \mathrm{C})$. For this procedure, an incision was made at the medial wall of the MHV trunk and a cryopreserved vein patch homograft was attached (Fig. 7D), which made the graft outflow vein orifice $4 \mathrm{~cm}$ in transverse diameter.

The recipient hepatectomy was performed according to standard procedure. The procedures for graft implantation were the same in the abovementioned case, except for biliary reconstruction through duct-to-duct anastomosis. The pathology report presented that there was diffuse glycogenesis with moderate fatty change and perivenular fibrosis, which was consistent with OTC deficiency (Fig. 5B). Notably, after LDLT, it was shown that right pleural effusion developed; thus, a percutaneous drainage was performed. This patient experienced acute cellular rejection (rejection activity index, 3 ) at 2 weeks after transplantation and recovered with augmentation of immunosuppression. On the early posttransplant CT image, the site of graft hepatic vein 

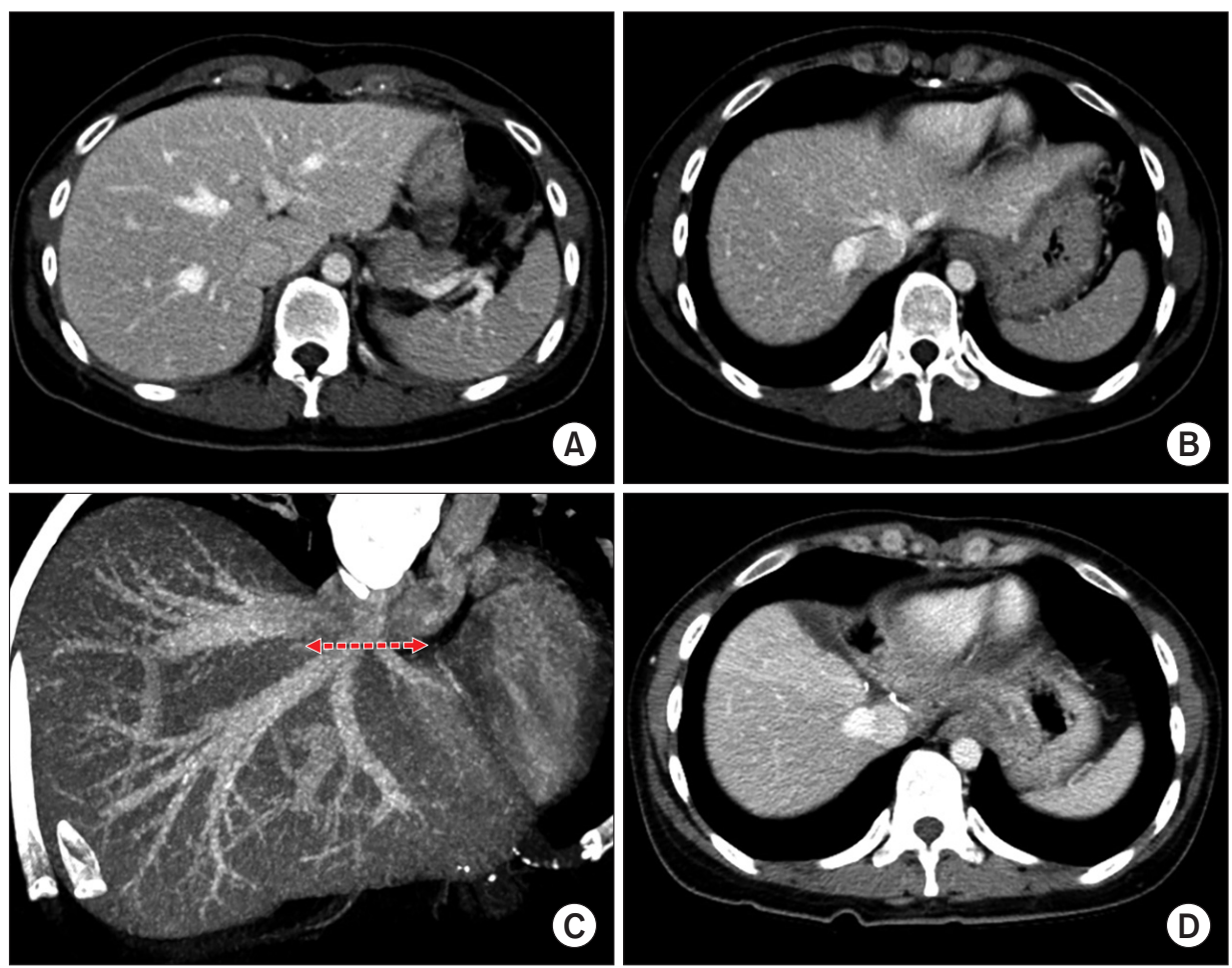

Fig. 6. Preoperative imaging studies of the living donor of case No. 2. Computed tomography scans show the shape of the left liver $(A)$ and the anatomy of the left and middle hepatic veins $(B, C)$. The arrow indicates the line of hepatic vein transection. (D) Computed tomography performed 1 week after the operation shows the location of hepatic vein transection by an endovascular stapler.
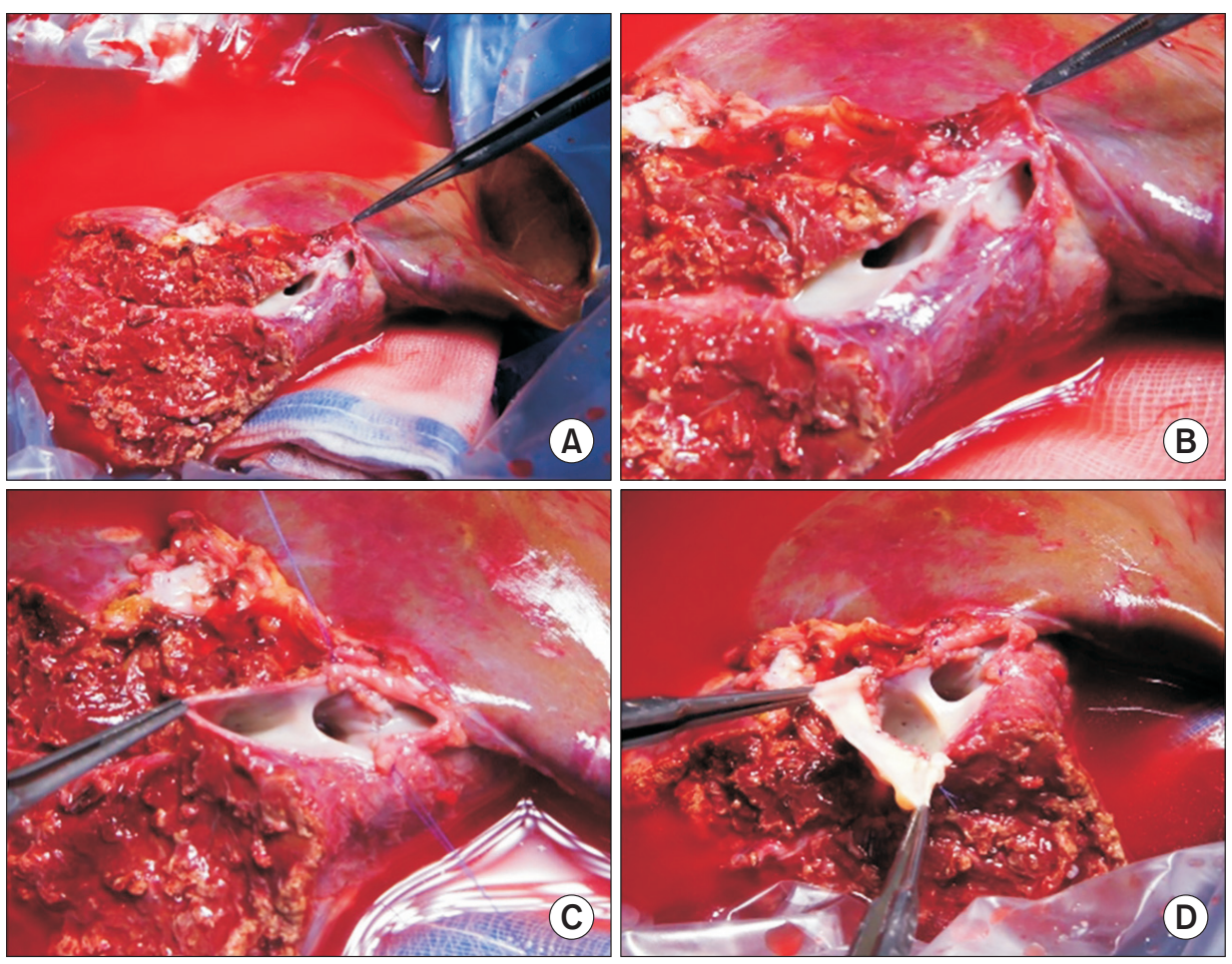

Fig. 7. Intraoperative photographs of the graft hepatic vein venoplasty on the back table in case No. 2. There were two separate openings of the middle hepatic vein (MHV), with segment III vein and segment II vein at the graft (A, B). (C) A unification septoplasty was performed. An incision was made at the medial wall of the MHV trunk, and a cryopreserved vein homograft patch was attached (D), which made the graft outflow vein orifice $4 \mathrm{~cm}$ in transverse diameter. 

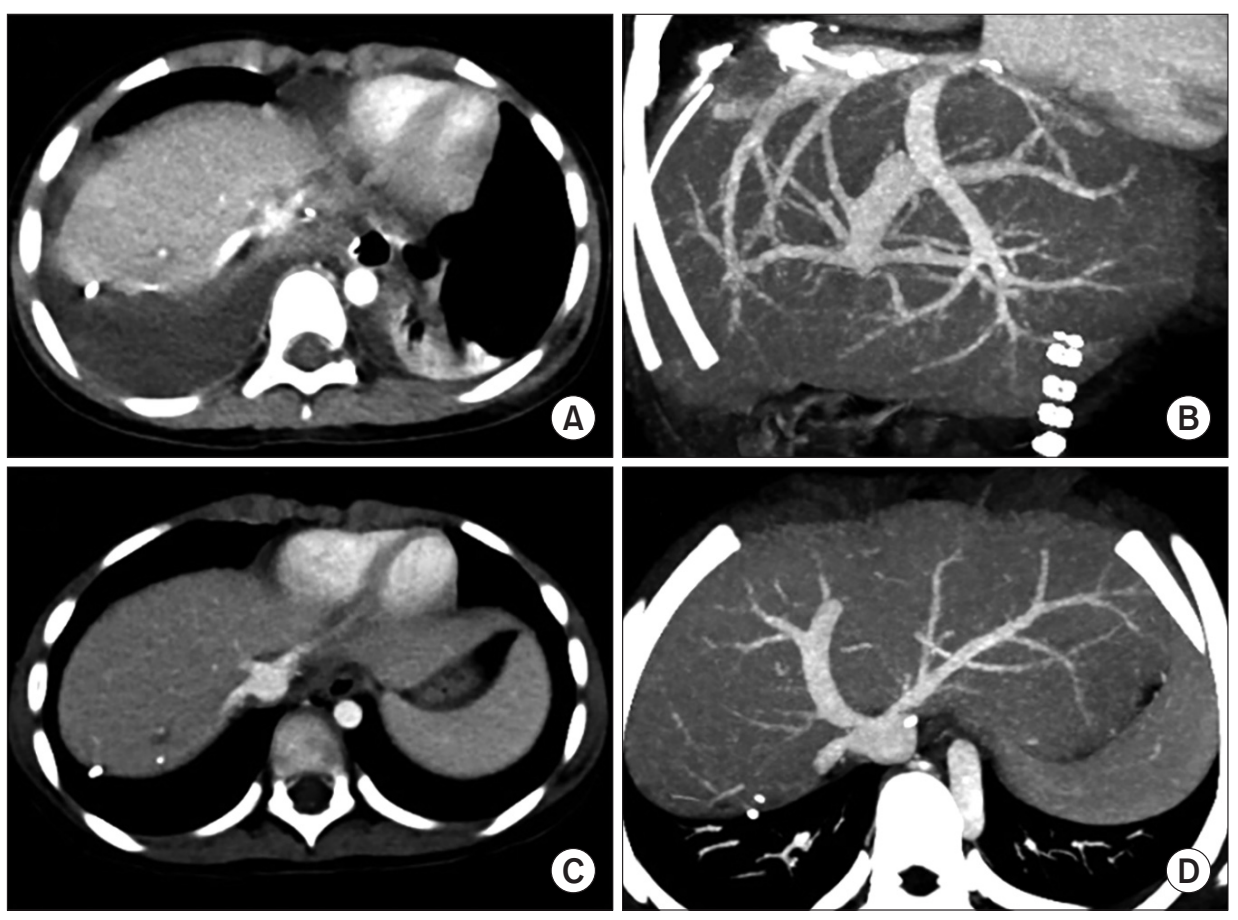

Fig. 8. Posttransplant computed tomography (CT) follow-up of case No. 2. CT scan obtained 12 days after transplantation shows right pleural effusion (A) and slight compression of the graft hepatic vein reconstruction (B). CT scans obtained 4 months after transplantation show normal configuration of the graft hepatic vein reconstruction (C, D).

reconstruction appeared to be compressed (Fig. 8A and B), but such a configuration was normalized after resolution of acute cellular rejection and loss of pleural effusion (Fig. 8C and D). At 4 months after transplantation, biliary stricture developed at the anastomosis site, which was successfully treated with an endoscopic retrograde biliary drainage tube and using a retrievable metallic wall stent. The patient has been doing well for 4 years to date.

\section{DISCUSSION}

Pediatric LDLT is vulnerable to vascular complications primarily because the graft and recipient vessels are smaller than in adult LDLT; thus, surgical techniques ensuring secure vascular reconstruction should be used in these cases. Regarding graft hepatic vein reconstruction, making the graft hepatic vein suitable for anastomosis on the back table is the most effective method to prevent hepatic vein outflow obstruction. We have developed various surgical techniques of hepatic vein venoplasty for various types of partial liver grafts [7-10].

Compared with the usual LL grafts harvested through an open surgery, those harvested through a laparoscopic approach have a definite drawback in the graft hepat- ic vein. It is noted that a laparoscopically harvested LL graft usually has separate openings for the LHV and MHV trunks, as shown in our two cases. The common LHVMHV trunk of the donor is stapled at the donor and graft sides using an endoscopic vascular stapler, and the stapled stump at the graft should be excised to drain the graft hepatic vein orifice [5]. This process results in an additional removal of the graft hepatic vein stump, compared with open surgery. Since such a hepatic vein orifice of a LL graft is not suitable for direct anastomosis, a customized hepatic vein that is individually designed for the graft and recipient is necessary to perform secure outflow vein reconstruction.

For designing hepatic vein venoplasty for a LL graft, several graft and recipient factors should be taken into account. First, the size of the recipient hepatic vein orifice at the IVC should be assessed before any design could be made in the case. It is not possible to measure the size before removal of the recipient's native liver, but there are ways to empirically estimate the size of the recipient hepatic vein orifice. For pediatric patients weighing around $20 \mathrm{~kg}$, similar to our cases, the stretched transverse diameter of a recipient hepatic vein orifice is usually $4 \mathrm{~cm}$. In contrast, it is often increased to $5 \mathrm{~cm}$ in adolescent and adult recipients. The second factor for consideration is the GRWR. If the GRWR exceeds $2 \%$ in pediatric patients 
older than 3 years of age, we intentionally remove the intervening liver parenchyma between the LHV and MHV to form a common channel at the graft hepatic vein orifice, which is beneficial to tolerate the extrinsic graft compression by accommodation of a large-sized graft. The third factor is the shape and size of the separate graft hepatic vein openings. Various techniques are used for unification of these hepatic vein orifices, including the procedures of simple unification, unification after septotomy, and unification after septotomy and parenchymal excision. The fourth factor is availability of the vein homograft. The medial wall of the MHV trunk at a laparoscopically harvested LL graft is usually short and weak, a condition not suitable for direct anastomosis. Likewise, attachment of a vein patch makes the medial wall of the MHV trunk suitable for suturing. The size of a vein patch is dependent on the required target diameter of the graft hepatic vein orifice, which is a requirement for one-to-one matching with the recipient hepatic vein orifice. These four components were integrated in the design of the graft hepatic vein venoplasty in our cases.

A superficial branch of the LHV is identified in a considerable proportion of LL or left lateral section grafts $[11,12]$. Although this vein is small, it can be used for venoplasty, by which the actual cross-sectional area of the LHV anastomosis can be slightly increased, as shown in our case No. 1. Based on our experience, any superficial branch of the LHV regardless of size can be effectively used for unification venoplasty.

Any vein patch can be used for a patch venoplasty of the graft hepatic vein orifice. If necessary, the living donor's gonadal or ovarian vein can be harvested because the pediatric recipient's veins are too small to use for venoplasty. If a vein homograft is available, it is the best material for making a sizable vein patch. Currently, cryopreserved femoral vein and artery homografts are available through the Korea Public Tissue Bank. The cryopreserved external iliac vein homografts used in our cases were obtained from the institutional tissue bank of our institution. All human tissues stored at the tissue bank were donated after informed consent was provided by the donor's family members. All procedures for vascular tissue procurement and processing were performed in compliance with Korean legislation and, therefore, conformed to the ethical and safety concerns for therapeutic use [13].

In conclusion, the laparoscopically harvested LL grafts has a drawback of widely separate graft hepatic vein openings; thus, a unification venoplasty of customized design individually tailored for the $\mathrm{LL}$ graft and pediatric recipient is required to ensure a secure graft hepatic vein reconstruction.

\section{ACKNOWLEDGMENTS}

\section{Conflict of Interest}

Shin Hwang is an editorial board member of the journal but did not involve in the peer reviewer selection, evaluation, or decision process of this article. No other potential conflicts of interest relevant to this article were reported.

\section{Funding/Support}

This study was supported by research grant from the Korean Society for Transplantation (2020-00-03003-006).

\section{ORCID}

Jung-Man Namgoong https://orcid.org/0000-0002-9237-7440

Shin Hwang https://orcid.org/0000-0002-9045-2531 Ki-Hun Kim https://orcid.org/0000-0002-4016-0995 Gil-Chun Park https://orcid.org/0000-0003-1631-3258 Kyung Mo Kim https://orcid.org/0000-0001-7896-6751 Seak Hee Oh https://orcid.org/0000-0002-9672-8877 Hwui-Dong Cho https://orcid.org/0000-0001-8501-3385 Hyunhee Kwon https://orcid.org/0000-0001-6647-9155 Yong Jae Kwon https://orcid.org/0000-0001-9490-1229

\section{Author Contributions}

Conceptualization: SH. Data curation: JMN, KMK, SHO. Methodology: KHK, GCP, HDC, HK, YJK. Visualization: SH. Writing-original draft: SH, JMN. Writing-review \& editing: $\mathrm{SH}$.

\section{REFERENCES}

1. Scatton O, Katsanos G, Boillot O, Goumard C, Bernard D, Stenard F, et al. Pure laparoscopic left lateral sectionectomy in living donors: from innovation to development in France. Ann Surg 2015;261:506-12.

2. Broering DC, Elsheikh $Y$, Shagrani M, Abaalkhail F, Troisi RI. Pure laparoscopic living donor left lateral sectionectomy in pediatric transplantation: a propensity score analysis on 220 consecutive patients. Liver Transpl 
2018;24:1019-30.

3. Gautier S, Monakhov A, Gallyamov E, Tsirulnikova O, Zagaynov E, Dzhanbekov T, et al. Laparoscopic left lateral section procurement in living liver donors: a single center propensity score-matched study. Clin Transplant 2018;32:e13374.

4. Soubrane O, de Rougemont O, Kim KH, Samstein B, Mamode N, Boillot O, et al. Laparoscopic living donor left lateral sectionectomy: a new standard practice for donor hepatectomy. Ann Surg 2015;262:757-61.

5. Almodhaiberi $\mathrm{H}$, Kim SH, Kim KH. Totally laparoscopic living donor left hepatectomy for liver transplantation in a child. Surg Endosc 2018;32:513.

6. Kim KH, Jung DH, Park KM, Lee YJ, Kim DY, Kim KM, et al. Comparison of open and laparoscopic live donor left lateral sectionectomy. Br J Surg 2011;98:1302-8.

7. Hwang S, Ha TY, Ahn CS, Moon DB, Kim KH, Song GW, et al. Standardized surgical techniques for adult living donor liver transplantation using a modified right lobe graft: a video presentation from bench to reperfusion. Korean J Hepatobiliary Pancreat Surg 2016;20:97101.

8. Hwang S, Lee SG, Ahn CS, Moon DB, Kim KH, Sung KB, et al. Morphometric and simulation analyses of right hepatic vein reconstruction in adult living donor liver transplantation using right lobe grafts. Liver Transpl 2010;16:639-48.

9. Hwang S, Lee SG, Ha TY, Ahn CS, Park KM, Kim KH, et al. Simplified standardized technique for living donor liver transplantation using left liver graft plus caudate lobe. Liver Transpl 2004;10:1398-405.

10. Hwang S, Lee SG, Ha TY, Ahn CS, Park KM, Kim KH, et al. Feasibility assessment for tailoring preservation of segment VIII hepatic vein during left liver graft procurement. Hepatogastroenterology 2006;53:928-32.

11. Imamura $H$, Makuuchi $M$, Sakamoto $Y$, Sugawara $Y$, Sano K, Nakayama A, et al. Anatomical keys and pitfalls in living donor liver transplantation. J Hepatobiliary Pancreat Surg 2000;7:380-94.

12. Namgoong JM, Hwang S, Park GC, Kwon H, Kwon YJ, Kim SH. Graft outflow vein unification venoplasty with superficial left hepatic vein branch in pediatric living donor liver transplantation using a left lateral section graft. Ann Hepatobiliary Pancreat Surg 2020;24:32632.

13. Kwon $\mathrm{H}$, Kwon $\mathrm{H}$, Hong JP, Han $\mathrm{Y}$, Park $\mathrm{H}$, Song GW, et al. Use of cryopreserved cadaveric arterial allograft as a vascular conduit for peripheral arterial graft infection. Ann Surg Treat Res 2015;89:51-4. 